\title{
A phase I clinical trial utilizing autologous tumor-infiltrating lymphocytes in patients with primary hepatocellular carcinoma
}

\author{
Shan-Shan Jiang ${ }^{1, *}$, Yan Tang ${ }^{1, *}$, Yao-Jun Zhang ${ }^{2, *}$, De-Sheng Weng1, Zhong-Guo \\ Zhou $^{2}$, Ke Pan ${ }^{1}$, Qiu-Zhong Pan ${ }^{1}$, Qi-Jing Wang ${ }^{1}$, Qing Liu ${ }^{1}$, Jia He ${ }^{1}$, Jing-Jing Zhao ${ }^{1}$, \\ Jiang Li ${ }^{1}$, Min-Shan Chen ${ }^{2}$, Alfred E. Chang ${ }^{3}$, Qiao Li ${ }^{3}$, Jian-Chuan Xia ${ }^{1}$ \\ ${ }^{1}$ Department of Biotherapy, Sun Yat-sen University Cancer Center, State Key Laboratory of Oncology in South China, \\ Collaborative Innovation Center for Cancer Medicine, Guangzhou, China \\ ${ }^{2}$ Department of Hepatobiliary Oncology, Sun Yat-sen University Cancer Center, Guangzhou, China \\ ${ }^{3}$ University of Michigan Comprehensive Cancer Center, Ann Arbor, Michigan, USA \\ *These authors have contributed equally to this work
}

Correspondence to:

Jian-Chuan Xia, e-mail: xiajch@mail.sysu.edu.cn

Qiao Li, e-mail: qiaoli@umich.edu

Keywords: primary hepatocellular carcinoma, autologous tumor-infiltrating lymphocytes, adoptive cell therapy

Received: July 15,2015 Accepted: September 01, $2015 \quad$ Published: October 20, 2015

\section{ABSTRACT}

This report describes an ongoing Phase I clinical trial testing the safety of adoptive cell therapy (ACT) using autologous tumor-infiltrating lymphocytes (TIL) in patients with primary hepatocellular carcinoma (HCC). Fifteen HCC patients were treated with their activated and expanded TILs following tumor resection. From a total of 17 patients with HCC, TIL were successfully expanded from 15 patients $(88 \%)$, whereas two patients showed minimal or no expansion of TIL. Transient increase in the frequency of $T$ cells was observed after adoptive transfer who was found only associated with grade I flu-like symptoms and malaise. After a median follow-up of 14 months, 15 patients ( $100 \%)$ were alive; and 12 patients $(80 \%)$ showed no evidence of disease, 3 patients (patient $1,11,12$ ) had tumor recurrence. The time to the diagnosis of tumor recurrence following therapy ranged from 105 to 261 days. These results indicate that immunotherapy with activated and expanded autologous TIL could be successfully performed with low toxicity, thus would serve as a novel treatment modality for patients with HCC.

\section{INTRODUCTION}

Hepatocellular carcinoma (HCC) is one of the most prevalent and lethal malignancies worldwide. It is the fifth most common cancer and ranks as the third leading cause of cancer-related deaths. In China, current treatment options for early-stage HCC include surgery, transarterial chemoembolization (TACE) and molecular targeted therapy. However, the overall outcome of such efforts towards HCC is disappointing, with only $10-20 \%$ of tumors resectable at the time of diagnosis, and the five-year survival is poor compared with other gastrointestinal malignancies $[1,2]$.

Previously, patients with advanced HCC did not have very much therapeutic options. A major milestone in the treatment for this disease was the clinical use of sorafenib. Sorafenib, a multikinase inhibitor targeting the Raf serine/ threonine kinases and the VEGF receptor 1-3 (VEGFR1-3), PDGF receptor (PDGFR)-b, c-Kit, fms-like tyrosine kinase-3 (FLT-3) and p38 tyrosine kinases [3], was the first approved molecule-targeted agent that demonstrated survival benefits in patients with advanced HCC in 2007 [4, 5]. It inhibits tumor-cell proliferation and tumor angiogenesis and increases the rate of apoptosis in a wide range of tumor models $[6,7]$. The clinical success of sorafenib occurred when two pivotal studies, the SHARP and Asian Pacific trials, showed survival benefits over best supportive care $[8,9]$. These results have led to the approval of sorafenib by regulatory agencies as the first systemic treatment in the advanced HCC and have served as a major impetus to recent research in the field.

Immunotherapy is emerging as a new treatment stratage for tumors, which has been cosidered as the fourth treatment option following surgery, chemotherapy 
and radiotherapy. Immunotherapy has proved to play an important role in the comprehensive treatment of tumors [10]. For example, the success of immunotherapy in advanced prostate cancer suggested its significant role in cancer treatment [11]. Adoptive cell therapy (ACT) is a highly personalized form of passive immune therapy based on the infusion of autologous $\mathrm{T}$ cells that are activated and expanded ex vivo [12]. Tumor-infiltrating lymphocytes (TILs) are a type of white blood cells found in tumor, and are implicated to be tumor-reactive. The presence of TIL in tumors is often associated with improved clinical outcomes $[13,14]$. TILs are frequently found in tumor, suggesting tumor immunogenicity and immune response to tumor antigens in the host. These antigens distinguish the tumor from healthy cells, thereby providing an immunological stimulus [15]. Clinical-grade TIL generation for human therapy is a biphasic process, consisting of initial expansion in IL-2-containing medium of TILs obtained from tumor fragments or digests (prerapid expansion protocol [REP] phase). Following a standard 14-day REP, the TILs are activated with antiCD3 antibody and irradiated allogeneic peripheral blood mononuclear cells (PBMCs) [16]. Rosenberg and colleagues previously described TIL treatment of patients with advanced melanoma in three clinical trials at the NIH Clinical Center. Improved patient outcome was observed when TILs were used compared with lymphokine activated killer cells (LAKs) [17]. Recently, phase II trials have illustrated strong potential of TIL in malignancy therapy, with promising cure rates of $20-40 \%$ [18]. Previous studies have demonstrated remarkable correlations between tumor prognosis and the number as well as the component of TILs in HCC $[19,20]$. Therefore, isolating, stimulating and amplifying TIL from HCC could potentially represent a novel immunotherapy against HCC.

\section{RESULTS}

\section{Patient characteristics}

Fifteen patients were enrolled in the study, and all patients presented with HCC without distant organ metastasis at diagnosis. Among the 15 patients, 14 were male and 1 was female. The average age was 46.7 years (range, 31-66 years). Three patients had a performance status (PS) of 1; all others had a PS of 0. All fifteen patients had hepatic $B$ virus infection, underwent radical resection prior to receiving TIL therapy and were followed-up to monitor toxicity. The median follow-up period was 14 months (range, 12-16 months).

\section{In vitro expansion and characterization of TIL}

TILs were successfully generated from all 15 patients with HCC recruited for the study. TILs from all patients were activated and expanded within $27.9 \pm 3.05$ days (range, 23-33 days) using the method described in the Materials. TIL cultures were either cryopreserved or used directly for large-scale expansion. All cultures were expanded to treatment levels. TILs were administered at an average of 27.7 days after surgery.

To evaluate basic TIL characteristics, fluorescenceactivated cell sorting (FACS) analysis was performed and IFN- $\gamma$ expression was assessed after PFA stimulation. The $\mathrm{T}$ cells generated for therapy contained a high frequency of $\mathrm{CD}^{+}$lymphocytes, ranging from $86.2 \%$ to $99.2 \%$ (average, $95.8 \%$ ). These $\mathrm{CD}^{+}$populations contained a number of heterogeneous $\mathrm{CD}^{+} \mathrm{T}$ cells, ranging from $20.7 \%$ to $82.3 \%$ (average, $42.7 \%$ ), and a number of $\mathrm{CD}^{+}$ $\mathrm{T}$ cells, ranging from $18 \%$ to $80.5 \%$ (average, $50.5 \%$ ), and a number of $\mathrm{CD}^{2} 6^{+} \mathrm{T}$ cells, ranging from $2.2 \%$ to $36.4 \%$ (average, 14\%).Futhermore, The average $\mathrm{CD}^{+} \mathrm{CD} 27^{+}$ frequency is ranging from $9.2 \%$ to $59.8 \%$ (average, $25.3 \%$ ) (Table 1).

To determine the immune response of TIL after expansion, the cytokine profiles were evaluated, including type 1 cytokines IFN- $\gamma$ and TNF- $\alpha$ and type 2 cytokine IL-4, in TIL cultures from 15 HCC patients treated with PMA/ionomycin (Table 1). The TIL cultures contained a high percentage of $\mathrm{CD}^{+} \mathrm{IFN}-\gamma$ producing T cells $(38.76 \%$ $\pm 20.3 \%)$ and $\mathrm{CD}^{+} \mathrm{TNF}-\alpha$ producing $\mathrm{T}$ cells $(32.7 \% \pm$ $13.7 \%$ ), and a low percentage of $\mathrm{CD}^{+}$IL-4 producing $\mathrm{T}$ cells $(5.1 \% \pm 2.8 \%)$. These results suggest that the TIL cultures genarated from HCC patients were prioritized to secret type 1 cytokines after $\mathrm{T}$ cell receptor stimulation in this study.

In the present research, there are striking differences in the relative proportions of CD4, CD8 and CD56 cells. We have performed the correlation analysis for proportions of CD4, CD8, and CD56 cells with patient's tumor type, cytokine production, and toxicity. The results are shown in Table 2 . In the correlation analysis, we found that the proportions of CD4, CD8 cells are significantly $(P<0.05)$ correlated with the levels of IFN- $\gamma$ and TNF- $\alpha$. However, the proportions of CD4, CD8, and CD56 cells are not significantly $(P>0.05)$ correlated with other clinicopathological parameters, including tumor type, IL-4, and toxicity. Due to the reason that only 15 patients were enrolled in the present phase I trial, the toxicity was summarized as either absent or present, instead of detailed toxicity reactions.

\section{Safety analysis of TIL-based immunotherapy}

Of the 15 patients for whom TILs were generated, 12 received one T-cell infusion, and three patients received two T-cell infusions. Infusion of TIL was safe and resulted in grade I and /or II toxicities, including flu-like symptoms, malaise, leucopenia and neutropenia (Table 3). Patient 1 showed a flu-like symptoms, malaise. 
Table 1: Characteristics of infused TILs

\begin{tabular}{|c|c|c|c|c|c|c|c|c|}
\hline \multirow[t]{2}{*}{ Patients } & \multicolumn{5}{|c|}{ Infused TILs (\%) } & \multicolumn{3}{|c|}{$\mathrm{CD8}^{+}$cells } \\
\hline & CD3 & CD4 & CD8 & CD56 & $\mathrm{CD8}^{+} \mathrm{CD}^{2} 7^{+}$ & IFN- $\gamma$ & TNF- $\alpha$ & IL-4 \\
\hline 01 & 97.8 & 63.5 & 31.7 & 11.1 & 22.4 & 18.5 & 26.3 & 4.5 \\
\hline 02 & 99.2 & 80.5 & 20.7 & 7.3 & 15.9 & 31.3 & 32.6 & 5.4 \\
\hline 03 & 99.2 & 56 & 43.2 & 13 & 36.6 & 26.8 & 20.7 & 6.1 \\
\hline 04 & 98.4 & 18 & 80.3 & 5.7 & 13.7 & 70.4 & 62.6 & 1.1 \\
\hline 05 & 94.8 & 48.3 & 44 & 15.5 & 19.7 & 34.6 & 37.3 & 4.1 \\
\hline 06 & 90.8 & 79 & 11.7 & 3.7 & 25.7 & 11.6 & 10.8 & 2.5 \\
\hline 07 & 94.7 & 78 & 16.5 & 10.6 & 12.1 & 13.5 & 12.6 & 7.8 \\
\hline 08 & 98.7 & 16.7 & 82.3 & 2.2 & 26.6 & 79.8 & 51.4 & 5.3 \\
\hline 09 & 98.7 & 41.6 & 49.2 & 30.4 & 51.8 & 46.8 & 33 & 6 \\
\hline 10 & 96.9 & 54.4 & 42.1 & 20 & 25.3 & 66.1 & 37.6 & 2.6 \\
\hline 11 & 92.1 & 49.6 & 30.2 & 23.8 & 9.2 & 23.4 & 19.7 & 1.5 \\
\hline 12 & 96 & 62.1 & 30.7 & 6.1 & 13.4 & 35.7 & 42.2 & 2.8 \\
\hline 13 & 86.2 & 31.2 & 44.6 & 36.4 & 25.3 & 43.6 & 36.2 & 28.5 \\
\hline 14 & 96.8 & 28.4 & 66.3 & 13.2 & 59.8 & 38.5 & 34.9 & 8.2 \\
\hline 15 & 97.2 & 50.3 & 46.3 & 13.2 & 22 & 40.8 & 32.8 & 10.5 \\
\hline Total average & $\begin{array}{c}95.8 \pm \\
3.66\end{array}$ & $\begin{array}{c}50.5 \pm \\
20.6\end{array}$ & $\begin{array}{c}42.7 \pm \\
20.9\end{array}$ & $14 \pm 9.8$ & $25.3 \pm 14.3$ & 38.76 & 32.7 & 5.12 \\
\hline
\end{tabular}

Table 2: Correlation analysis of the proportions of CD4, CD8, and CD56 with patient's tumor type, cytokine production, toxicity

\begin{tabular}{|l|c|c|c|}
\hline \multicolumn{2}{l|}{ CD4 } & CD8 & $P=0.269$ \\
\hline Tumor type & $P=0.309$ & & \\
\hline Cytokine production & & $P=0.002(r=0.722)$ & $P=0.860$ \\
\hline IFN- $\gamma$ & $P=0.004(r=-0.669)$ & $P=0.004(r=-0.695)$ & $P=0.880$ \\
\hline TNF- $\alpha$ & $P=0.007(r=-0.661)$ & $P=0.319$ & $P=0.130$ \\
\hline IL-4 & $P=0.846$ & $P=0.827$ & $P=0.507$ \\
\hline Toxicity & $P=0.913$ & & \\
\hline
\end{tabular}

Table 3: Toxicity of T-cell therapy in patients with HCC $(n=15)$

Symptoms
\begin{tabular}{|l|c|c|c|c|c|}
\hline Flu-like symptoms & G0 & G1 & G2 & - G3 & - \\
\hline malaise & $14 / 15$ & $1 / 15$ & - & - & - \\
\hline leucopenia & $13 / 15$ & $2 / 15$ & - & - & - \\
\hline neutropenia & $13 / 15$ & $2 / 15$ & - & - & - \\
\hline
\end{tabular}


He was administered with acetaminophen. Four patients experienced Grade 1 toxicities of leucopenia, neutropenia. No grade III/IV serious adverse events occurred in a total of 18 instances of cell injection. These toxicity gradings were assigned according to the National Cancer Institute Common Toxicity Criteria Scale 2.0.

\section{Clinical observations following infusion of TIL}

After a median follow-up of 14 months, 15 patients (100\%) were alive; and 12 patients $(80 \%)$ showed no evidence of disease, 3 patients (patient 1,11,12) had tumor recurrence.

The time to the diagnosis of tumor recurrence following therapy ranged from 105 to 261 days (patient 1:170 days, patient 11:105 days, patient 12: 261 days) (Table 4). Patient 2 showed the longest no evidence of disease with ongoing 454 days.

\section{Immunologic and virological responses following infusion of TIL}

In the final set of our experiments, comprehensive longitudinal ex vivo profiling of $\mathrm{HBV}$ load were conducted. In addition, alpha-fetoprotein (AFP) was detected in the peripheral blood of patients with HCC who had been treated with ACT.
To evaluate the plasma HBV load and AFP level, which have previously been correlated to disease status in patients with HCC [21, 22], qRT-PCR was performed on plasma samples prior to surgery and one month after infusion. As shown in Figure 1, HBV load (Figure 1A) and AFP level (Figure 1B) were either unchannged or decresed after $\mathrm{T}$ cell infusion. There were statistically significant changes both in HBV load $(p=0.0001)$ and in AFP ( $p=$ 0.0067). Additionally, the decrease of AFP and HBV level is the main cause of the reduction of the tumor burden caused by the surgical removal of the lesion.

\section{DISCUSSION}

To our knowledge, this is the first phase I clinical trial involving ACT using ex vivo expanded autologous TILs after surgery as a novel treatment strategy for HCC patients. The data presented here show that infusion of autologous TILs was feasible and safe in this patient population.

Surgery is the most effective treatment for $\mathrm{HCC}$, yet over $75 \%$ of HCC patients develop recurrence and/or metastasis within 5 years after surgery, which is the main cause of death for these individuals [23]. HCC possesses several characteristics that render it an attractive target for immunotherapy. For example, there is active recruitment of TILs that are able to recognize tumor-specific antigens

Table 4: Patients with HCC treated with adoptively transferred TILs

\begin{tabular}{|c|c|c|c|c|c|c|}
\hline $\begin{array}{l}\text { Subject } \\
\text { code }\end{array}$ & $\begin{array}{l}\text { Days of T-cell infusion } \\
\text { after the tumor tissue } \\
\text { was obtained }\end{array}$ & Cells per infusion & $\begin{array}{l}\text { Number } \\
\text { of } \\
\text { infusions }\end{array}$ & Clinical response & DFS (d) & OS (d) \\
\hline 01 & 26 & $3 \times 10^{9}$ & 2 & Recurrence & 170 & $462^{+}$ \\
\hline 02 & 26 & $8.5 \times 10^{8}$ & 2 & NED & $454^{+}$ & $454^{+}$ \\
\hline 03 & 27 & $3.4 \times 10^{8}$ & 1 & NED & $438^{+}$ & $438^{+}$ \\
\hline 04 & 31 & $3.1 \times 10^{8}$ & 1 & NED & $438^{+}$ & $438^{+}$ \\
\hline 05 & 32 & $8.8 \times 10^{8}$ & 1 & NED & $431^{+}$ & $431^{+}$ \\
\hline 06 & 31 & $1 \times 10^{9}$ & 1 & NED & $431^{+}$ & $431^{+}$ \\
\hline 07 & 25 & $9.0 \times 10^{8}$ & 1 & NED & $427^{+}$ & $427^{+}$ \\
\hline 08 & 35 & $8.6 \times 10^{8}$ & 1 & NED & $427^{+}$ & $427^{+}$ \\
\hline 09 & 22 & $9 \times 10^{8}$ & 2 & NED & $425^{+}$ & $425^{+}$ \\
\hline 10 & 28 & $8.2 \times 10^{8}$ & 1 & NED & $424^{+}$ & $424^{+}$ \\
\hline 11 & 26 & $2.6 \times 10^{9}$ & 1 & Recurrence & 105 & $418^{+}$ \\
\hline 12 & 26 & $2.5 \times 10^{9}$ & 1 & Recurrence & 261 & $418^{+}$ \\
\hline 13 & 26 & $9.2 \times 10^{8}$ & 1 & NED & $404^{+}$ & $404^{+}$ \\
\hline 14 & 27 & $1.8 \times 10^{9}$ & 1 & NED & $355^{+}$ & $355^{+}$ \\
\hline 15 & 27 & $10^{9}$ & 1 & NED & $355^{+}$ & $355^{+}$ \\
\hline
\end{tabular}

+ : ongoing

NED: no evidence of disease 
A

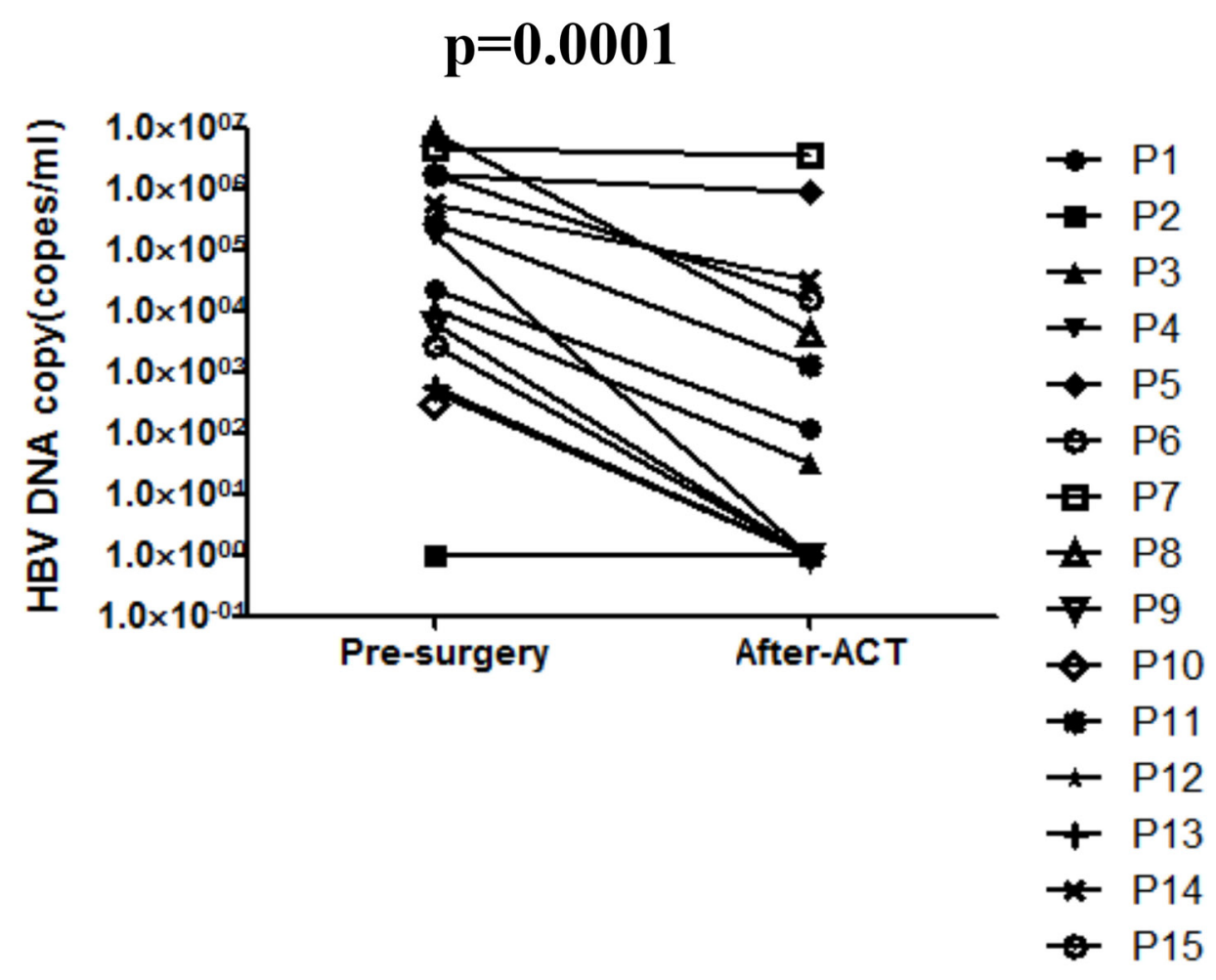

$\mathrm{B}$

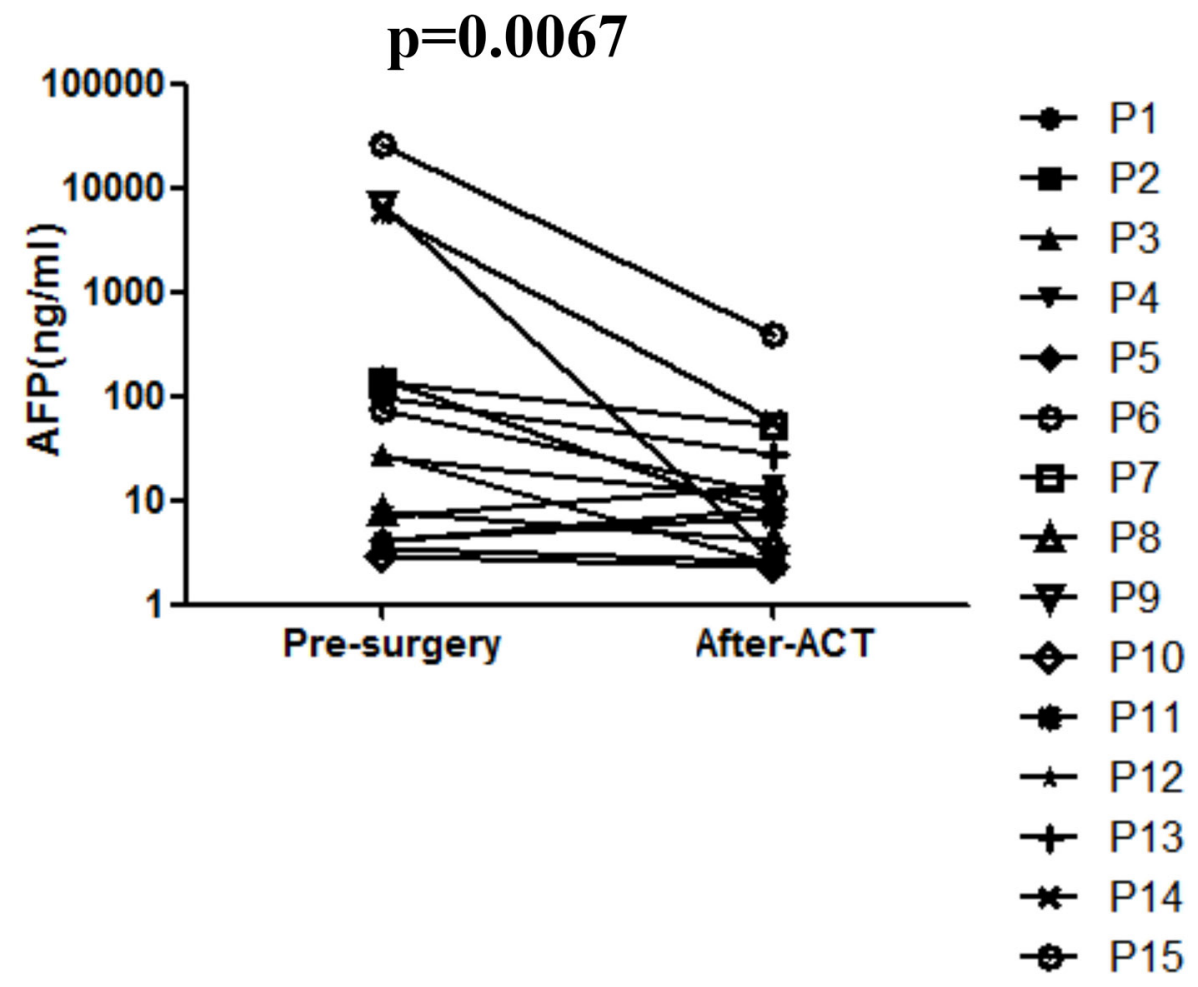

Figure 1: The impact of autologous TIL infusion on HBV load A. and AFP level B. Plasma samples taken prior to the surgery and after $\mathrm{T}$ cell infusion were assessed for HBV load and AFP level. 
as evidenced by their ability to lyse autologous tumor cells ex vivo [24]. In addition, TIL derived from HCC and expanded ex vivo in the presence of IL-2 displayed antitumor cytolytic activity [25].

TIL immunotherapy is a promising treatment method for cancer patients. Several researchers have demonstrated the benefit and safety of TIL immunotherapy for patients with malignancies in clinical studies [26-28]. A distinct advantage of TIL therapy is the broad nature of T-cell recognition of both defined and undefined tumor antigens against major histocompatibility complexes, in contrast to the single specificity and limited major histocompatibility complexes of the $\mathrm{T}$ cell receptor and chimeric antigen receptor transduction technologies.

The protocol described in this study was feasible in expanding tumor infiltrating lymphocytes from patients with primary HCC disease, and these expanded $\mathrm{T}$ cells have displayed high levels of IFN- $\gamma$ and TNF- $\alpha$ expression. One of the major advantages of this procedure is that a large number of T cells can be expanded within 4 weeks. Of the 17 patients with HCC, TILs were expanded from 15 patients $(88.2 \%)$, whereas there was minimal or no expansion of $\mathrm{T}$ cells from another 2 patients $(11.8 \%)$. These in vitro activated and expanded polyclonal T cells are composed of both $\mathrm{CD}^{+} \mathrm{T}$ cells and $\mathrm{CD}^{+} \mathrm{T}$ cells. Adoptive transfer of TIL was safe with minimal toxicities. The data presented in this study and in previously published work demonstrate that adoptive $\mathrm{T}$ cell therapy displays limited toxicity [29-31] and future studies should aim to develop more strategies to provide "of-the shelf" access for such therapies for HCC patients. In recent years, adoptive immunotherapy for HCC has been limited to using autologous T cells and dendritic cells (DC) from the PBMCs of patients, including cytokine-induced killer (CIK) cells, DC vaccination, and tumor-associated antigen glypican-3 (GPC3) -derived d peptide-specific cytotoxic T lymphocytes (CTLs) [32, 33]. Previous studies by Thomas and colleagues have shown that TIL can be used for the treatment of melanoma [34]. It will therefore be important to further explore the safety of TILs for patients with HCC.

As part of the secondary objectives of the current study, our clinical follow-up analyses of the patients showed that 15 patients $(100 \%)$ were alive; and 12 patients $(80 \%)$ showed no evidence of disease, 3 patients had tumor recurrence. The median overall survival of patients receiving $\mathrm{T}$ cell therapy was remarkably longer than our institutional average during the same period. However, these preliminary observations will require confirmation in a formal phase II randomized clinical trial.

Chronic Hepatitis B virus (HBV) infection and Hepatitis $\mathrm{C}$ virus (HCV) infection can lead to chronic hepatitis, liver cirrhosis, and hepatocellular carcinoma (HCC). HBV is the most important etiologic agent of liver cancer globally, particularly in high-prevalence areas of liver cancer. The world's first universal HBV vaccination program was launched in Taiwan in July 1984 [35]. The prevalence of $\mathrm{HCC}$ among recipients of the $\mathrm{HBV}$ vaccine has already decreased by $70 \%$ in comparison with those in the non-vaccinated group [36]. Besides timely HBV vaccination, the earlier administration of hepatitis $B$ immunoglobulin immediately after birth has proven to be an effective strategy to enhance the prevention of HBV infection and its related liver cancer. Before 2011, interferon (IFN)-based therapy, including dual therapy with pegylated interferon (PEG-IFN) plus ribavirin, was the standard care of HCV patients in most part of the world. Since 2011, several effective direct antiviral agents (DAAs) have been approved by the U.S. Food and Drug Administration for the treatment of HCC. Several trials have examined the impact of antiviral agents on HCVrelated HCC patients [37-40]. IFN-based therapy may decrease HCC incidence in HCV cirrhotic patients after $a$ $>$ 5-year follow-up; improve liver reserve; decrease HCC recurrence rate, and increase survival rate in $\mathrm{HCV}$-related HCC patients after curative HCC therapy.

Taken together, the results of the current study demonstrate that adoptive immunotherapy with TILs is safe and feasible in patients with HCC. These findings provide an important platform for future lager scale clinical trials with TIL-based immunotherapy in patients with HCC.

\section{MATERIALS AND METHODS}

\section{Study design}

This study was a phase I clinical trial assessing the use of TIL for adoptive cell therapy for patients with HCC. The study was approved by the Ethics Committee on Clinical Investigation of the Cancer Center of Sun Yatsen University (Guangdong, China) and is registered with Clinical Trials.gov (NCT01462903). Written informed consent was obtained from all participating individuals. The trial was carried out in accordance with the Helsinki declaration on experimentation on human subjects. The primary endpoint of this trial was to evaluate the safety of this therapy. The secondary endpoint was to investigate the immunological response and clinical outcome.

\section{Patient eligibility}

Patients with primary HCC in the Department of Hepatobiliary Oncology, Sun Yat-sen University Cancer Center from January 2014 to May 2014 were enrolled for this study. The eligibility criterias for patients participating in the clinical trial were as follows: (1) Patients were planned for radical resection; (2) Evaluation of clinical response in these patients was possible; (3) Child-Pugh scores were $\leq$ 9; (4) Eastern Cooperative 
Oncology Group (ECOG) performance status was 0-2; (5) Expected survival was at least 3 months; (6) Age of the patients was between 20-80 years; (7) Adequate bone marrow, cardiac, pulmonary and renal functions were present, including a white blood cell count of $>2000 /$ $\mathrm{mm}^{3}$, platelet count $>75000 / \mathrm{mm}^{3}$, total bilirubin $<1.5$ times the institutional normal upper limits, creatinine $<$ 1.5 times the institutional normal upper limits, and AST/ ALT/ALP $<2.5$ times the institutional normal upper limits; (8) Patients who had provided informed consent. The exclusion criterias of patients participating in the clinical trial were as follows: (1) Previous treatment with IL-12; (2) Pregnant or breastfeeding women, due to the potentially dangerous effects of the preparative chemotherapy on the fetus or infant; (3) Patients with active systemic infections, coagulation disorders or other major medical illnesses of the cardiovascular, respiratory or immune system, myocardial infarction, cardiac arrhythmias, obstructive or restrictive pulmonary disease; (4) Patients with any form of primary immunodeficiency (such as severe combined immunodeficiency disease); (5) Patients with concurrent opportunistic infections, as the experimental treatment being evaluated in this protocol depends on an intact immune system. Patients who have decreased immune competence may be less responsive to the experimental treatment and more susceptible to its toxicities; (6) Patients undergoing concurrent systemic steroid therapy; (7) Patients with concurrent autoimmune diseases. Patient characteristics are detailed in Table 5.
After patient enrollment and clinical verification of disease status, surgery to obtain tumor tissue was performed. Tumor tissue was used to expand TIL and to generate tumor lysate. As soon as successful TIL expansion was confirmed, patients received $\mathrm{T}$ cell infusion once or twice at two day intervals depending on the cell numbers obtained.

\section{Generation and characterization of tumor- infiltrating lymphocytes}

Bulk TILs were obtained from biopsied adjacenttumor tissues and expanded using an REP under conditions in accordance with current good manufacturing practices (GMP) in the Biotherapy Center at Sun Yat-sen University Cancer Center. Tumor specimens were sliced with a scalpel into small pieces of approximately $2-3 \mathrm{~mm}^{3}$ in size. Enzymatic digestion of the pieces was performed for 1.5 to 2 hours at $37^{\circ} \mathrm{C}$ with media containing collagenase IV $(0.1$ $\mu \mathrm{g} / \mathrm{ml}$ ) (Sigma-Aldrich, Saint Louis, USA). The obtained single-cell suspension was passed through a cell strainer, purified with a Ficoll gradient to collect TILs, washed twice with phosphate buffered saline (PBS).The TILs were then transferred to a 12 -well plate at a concentration of $1.0 \times 10^{6}$ cells $/ \mathrm{mL}$ in X-VIVO-15 medium (Lonza, Walkersville, USA) containing 10\% human AB serum and recombinant human IL-2 (2000 IU/ml, Four Rings BioPharmaceutiacl Co, Beijing, China) for cell expansion. Cell expansion generally required approximately 10 to

Table 5: Characteristics of patients with HCC enrolled in the phase I clinical trial

\begin{tabular}{|c|c|c|c|c|c|c|}
\hline $\begin{array}{l}\text { Subject } \\
\text { code }\end{array}$ & Age & Sex & ECOG & $\begin{array}{c}\text { Hepatic virus } \\
\text { infection }\end{array}$ & Cirrhosis & Prior therapy \\
\hline 01 & 66 & Male & 1 & HBV & No & Surgery \\
\hline 02 & 37 & Male & 0 & $\mathrm{HBV}$ & No & Surgery \\
\hline 03 & 33 & Male & 0 & $\mathrm{HBV}$ & Yes & Surgery \\
\hline 04 & 51 & Male & 0 & $\mathrm{HBV}$ & Yes & Surgery \\
\hline 05 & 59 & Male & 1 & $\mathrm{HBV}$ & Yes & Surgery \\
\hline 06 & 54 & Male & 0 & HBV & Yes & Surgery \\
\hline 07 & 56 & Male & 0 & $\mathrm{HBV}$ & Yes & Surgery \\
\hline 08 & 56 & Male & 1 & HBV & No & Surgery \\
\hline 09 & 52 & Male & 0 & HBV & No & Surgery \\
\hline 10 & 31 & Male & 0 & HBV & Yes & Surgery \\
\hline 11 & 40 & Male & 0 & $\mathrm{HBV}$ & Yes & Surgery \\
\hline 12 & 57 & Male & 0 & $\mathrm{HBV}$ & No & Surgery \\
\hline 13 & 41 & Female & 0 & $\mathrm{HBV}$ & No & Surgery \\
\hline 14 & 35 & Male & 0 & $\mathrm{HBV}$ & Yes & Surgery \\
\hline 15 & 33 & Male & 0 & $\mathrm{HBV}$ & Yes & Surgery \\
\hline
\end{tabular}


14 days. Short-term cultured TILs were then immediately cryopreserved or used directly for further large-scale cell activation and expansion. A total of 30-60 × $10^{6}$ TILs were activated and expanded to treatment levels by REP using an anti-CD3 antibody (OKT-3, $30 \mathrm{ng} / \mathrm{ml}$, BioHermes, Wuxi, China), $4000 \mathrm{IU} / \mathrm{mL}$ rhIL-2, and irradiated feeder cells as previously described [41].

\section{Adoptive cell transfer}

The $\mathrm{T}$ cell expansion of each patient is shown in Table 4. Patients who had successful $\mathrm{T}$ cell expansion received $1-2$ infusions of $0.3 \times 10^{9}$ to $3 \times 10^{9} \mathrm{~T}$ cells per infusion. None of the patients were administrated with IL2. Peripheral blood samples were harvested prior to the first infusion and up to 1 month post-infusion to assess the impact of T cell infusion on Peripheral blood cell count and to monitor plasma HBV load. Patients were monitored for tolerability and safety following T-cell infusion. Follow-up was in our outpatient department, and involved clinical and laboratory examinations 1 month after first infusion, every 3 months for the first 2 years, every 6 months during the third to fifth years, and annually for an additional 5 years or until death, whichever occurred first. MRI or computed tomographic scanning were conducted on patients to assess baseline tumor load prior to infusion and 1, 3, and 6 months after first infusion. Treatment responses were determined on the basis of WHO criteria and/or Response Evaluation Criteria in Solid Tumors (RECIST) (Figure 2).

\section{Immunologic monitoring assays}

TILs were collected and stained with the following antibodies: anti-CD3 (Pcy5), anti-CD4 (PE),
anti-CD8 (ECD), and anti-CD56 (APC) (Biolegend, CA).CD27 and CD28 surface expression was further tested after incubating TIL in complete medium without rhIL-2 for 48 hours. Isotype-matching antibodies were used as controls. After incubation at $4^{\circ} \mathrm{C}$ for $30 \mathrm{~min}$ with the above coupled antibodies and being washed with PBS, TILs were fixed with 4\% paraformaldehyde and analyzed using CytomicsFC500 Flow Cytometry (Beckman Coulter Inc., Fullerton, CA). Data analysis was performed using the CXP Analysis software (Beckman Coulter). For cytokine production assays, TILs were stimulated with paraformaldehyde (PMA) (Sigma, $50 \mathrm{ng} / \mathrm{ml}$ ) and ionomycin (Sigma, $500 \mathrm{ng} /$ $\mathrm{ml}$ ) for $4 \mathrm{~h}$ in the presence of Brefeldin A (Biolegend; $10 \mathrm{mg} / \mathrm{ml})$. Cells were then collected, washed and fixed with 4\% PMA for $5 \mathrm{~min}$ at room temperature (RT) and permeabilized with permeabilization buffer (eBioscience, San Diego, CA) for $10 \mathrm{~min}$ at RT. Cells were then labeled with anti-IFN- $\gamma$ (APC), anti-TNF- $\alpha$ (FITC), and anti-IL-4 (APC) and analyzed by flow cytometer.

\section{HBV DNA quantification}

All of the patients were tested for HBV DNA by means of quantitative real-time PCR using a COBAS AmpliPrep/COBAS TaqMan automated system (HBV Test, Roche Diagnostics, Bael, Switzerland). The HBV load was compared pre-surgery vs. after-ACT for each patient. Disease-free survival (DFS) was calculated from the time of surgery to the first detectable recurrence or progression, whereas overall survival (OS) was calculated from the time of surgery to the time of last follow-up.
Enrollment

Enrollment

Allocation

Allocated to intervention $(\mathrm{n}=17)$

Assessed for eligibility $(\mathrm{n}=18)$ .Received surgery and ACT $(\mathrm{n}=15)$

.Received surgery, Did not receive ACT (failed to grow sufficient TIL for infusion, $\mathrm{n}=2$ )

Follow-up

Analysis

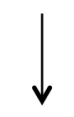

Lost to follow up (n=0)

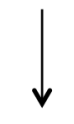

DFS and OS $(n=15)$

Figure 2: Phase I clinical trial profile using TIL for HCC patients. 


\section{Statistical analysis}

The HBV load and AFP from 15 patients who were pre-surgery and post-ACT were analyzed by paired $t$-test.

\section{ACKNOWLEDGMENTS AND FUNDING}

This work was supported by a grant from the Guangdong Province Science and Technology Plan Project, China (2011A030400004). This work was also supported in part by the Gillson Longenbaugh Foundation.

\section{CONFLICTS OF INTEREST} interests.

The authors declare that they have no competing

\section{REFERENCES}

1. Zhu AX. Systemic therapy of advanced hepatocellular carcinoma: how hopeful should we be? The oncologist. 2006; 11:790-800.

2. Bosch FX, Ribes J, Borras J. Epidemiology of primary liver cancer. Seminars in liver disease. 1999; 19:271-285.

3. Wilhelm SM, Carter C, Tang L, Wilkie D, McNabola A, Rong H, Chen C, Zhang X, Vincent P, McHugh M, Cao Y, Shujath J, Gawlak S, Eveleigh D, Rowley B, Liu L, et al. BAY 43-9006 exhibits broad spectrum oral antitumor activity and targets the RAF/MEK/ERK pathway and receptor tyrosine kinases involved in tumor progression and angiogenesis. Cancer Res. 2004; 64:7099-7109.

4. Llovet JM, Bruix J. Molecular targeted therapies in hepatocellular carcinoma. Hepatology. 2008; 48:1312-1327.

5. Llovet JM, Ricci S, Mazzaferro V, Hilgard P, Gane E, Blanc JF, de Oliveira AC, Santoro A, Raoul JL, Forner A, Schwartz M, Porta C, Zeuzem S, Bolondi L, Greten TF, Galle PR, et al. Sorafenib in advanced hepatocellular carcinoma. The New England journal of medicine. 2008; 359:378-390.

6. Lee SH, Song IH, Noh R, Kang HY, Kim SB, Ko SY, Lee ES, Kim SH, Lee BS, Kim AN, Chae HB, Kim HS, Lee TH, Kang YW, Lee JD, Lee HY. Clinical outcomes of patients with advanced hepatocellular carcinoma treated with sorafenib: a retrospective study of routine clinical practice in multi-institutions. BMC cancer. 2015; 15:236.

7. Shinoda M, Kishida N, Itano O, Ei S, Ueno A, Kitago M, Abe Y, Hibi T, Yagi H, Masugi Y, Tanabe M, Aiura K, Sakamaoto M, Tanimoto A, Kitagawa Y. Long-term complete response of advanced hepatocellular carcinoma treated with multidisciplinary therapy including reduced dose of sorafenib: case report and review of the literature. World journal of surgical oncology. 2015; 13:144.

8. Abou-Alfa GK, Johnson P, Knox JJ, Capanu M, Davidenko I, Lacava J, Leung T, Gansukh B, Saltz LB. Doxorubicin plus sorafenib vs doxorubicin alone in patients with advanced hepatocellular carcinoma: a randomized trial. Jama. 2010; 304:2154-2160.

9. Cheng AL, Kang YK, Chen Z, Tsao CJ, Qin S, Kim JS, Luo R, Feng J, Ye S, Yang TS, Xu J, Sun Y, Liang H, Liu J, Wang J, Tak WY, et al. Efficacy and safety of sorafenib in patients in the Asia-Pacific region with advanced hepatocellular carcinoma: a phase III randomised, double-blind, placebo-controlled trial. The Lancet Oncology. 2009; 10:25-34.

10. Lizee G, Overwijk WW, Radvanyi L, Gao J, Sharma P, Hwu P. Harnessing the power of the immune system to target cancer. Annual review of medicine. 2013; 64:71-90.

11. Schellhammer PF, Chodak G, Whitmore JB, Sims R, Frohlich MW, Kantoff PW. Lower baseline prostate-specific antigen is associated with a greater overall survival benefit from sipuleucel-T in the Immunotherapy for Prostate Adenocarcinoma Treatment (IMPACT) trial. Urology. 2013; 81:1297-1302.

12. Rosenberg SA, Dudley ME. Adoptive cell therapy for the treatment of patients with metastatic melanoma. Current opinion in immunology. 2009; 21:233-240.

13. Adams S, Gray RJ, Demaria S, Goldstein L, Perez EA, Shulman LN, Martino S, Wang M, Jones VE, Saphner TJ, Wolff AC, Wood WC, Davidson NE, Sledge GW, Sparano JA, Badve SS. Prognostic value of tumor-infiltrating lymphocytes in triple-negative breast cancers from two phase III randomized adjuvant breast cancer trials: ECOG 2197 and ECOG 1199. Journal of clinical oncology: official journal of the American Society of Clinical Oncology. 2014; 32:2959-2966.

14. Balermpas P, Michel Y, Wagenblast J, Seitz O, Weiss C, Rodel F, Rodel C, Fokas E. Tumour-infiltrating lymphocytes predict response to definitive chemoradiotherapy in head and neck cancer. British journal of cancer. 2014; 110:501-509.

15. Halapi E. Oligoclonal $\mathrm{T}$ cells in human cancer. Medical oncology. 1998; 15:203-211.

16. Dudley ME, Wunderlich JR, Shelton TE, Even J, Rosenberg SA. Generation of tumor-infiltrating lymphocyte cultures for use in adoptive transfer therapy for melanoma patients. Journal of immunotherapy. 2003; 26:332-342.

17. Topalian SL, Muul LM, Solomon D, Rosenberg SA. Expansion of human tumor infiltrating lymphocytes for use in immunotherapy trials. Journal of immunological methods. 1987; 102:127-141.

18. Rosenberg SA, Spiess P, Lafreniere R. A new approach to the adoptive immunotherapy of cancer with tumor-infiltrating lymphocytes. Science. 1986; 233:1318-1321.

19. Chew V, Tow C, Teo M, Wong HL, Chan J, Gehring A, Loh M, Bolze A, Quek R, Lee VK, Lee KH, Abastado JP, Toh HC, Nardin A. Inflammatory tumour microenvironment is associated with superior survival in hepatocellular carcinoma patients. Journal of hepatology. 2010; $52: 370-379$. 
20. Gao Q, Qiu SJ, Fan J, Zhou J, Wang XY, Xiao YS, Xu Y, Li YW, Tang ZY. Intratumoral balance of regulatory and cytotoxic T cells is associated with prognosis of hepatocellular carcinoma after resection. Journal of clinical oncology : official journal of the American Society of Clinical Oncology. 2007; 25:2586-2593.

21. Yu MW, Yeh SH, Chen PJ, Liaw YF, Lin CL, Liu CJ, Shih WL, Kao JH, Chen DS, Chen CJ. Hepatitis B virus genotype and DNA level and hepatocellular carcinoma: a prospective study in men. Journal of the National Cancer Institute. 2005; 97:265-272.

22. Ma WJ, Wang HY, Teng LS. Correlation analysis of preoperative serum alpha-fetoprotein (AFP) level and prognosis of hepatocellular carcinoma (HCC) after hepatectomy. World journal of surgical oncology. 2013; 11:212.

23. Tung SY, Wu CS. Risk factors for colorectal adenomas among immediate family members of patients with colorectal cancer in Taiwan: a case-control study. The American journal of gastroenterology. 2000; 95:3624-3628.

24. Yoong KF, Afford SC, Jones R, Aujla P, Qin S, Price K, Hubscher SG, Adams DH. Expression and function of CXC and $\mathrm{CC}$ chemokines in human malignant liver tumors: a role for human monokine induced by gamma-interferon in lymphocyte recruitment to hepatocellular carcinoma. Hepatology. 1999; 30:100-111.

25. Friedl J, Stift A, Paolini P, Roth E, Steger GG, Mader R, Jakesz R, Gnant MF. Tumor antigen pulsed dendritic cells enhance the cytolytic activity of tumor infiltrating lymphocytes in human hepatocellular cancer. Cancer biotherapy \& radiopharmaceuticals. 2000; 15:477-486.

26. Khammari A, Knol AC, Nguyen JM, Bossard C, Denis MG, Pandolfino MC, Quereux G, Bercegeay S, Dreno B. Adoptive TIL transfer in the adjuvant setting for melanoma: long-term patient survival. Journal of immunology research. 2014; 2014:186212.

27. Dudley ME, Gross CA, Somerville RP, Hong Y, Schaub NP, Rosati SF, White DE, Nathan D, Restifo NP, Steinberg SM, Wunderlich JR, Kammula US, Sherry RM, Yang JC, Phan GQ, Hughes MS, et al. Randomized selection design trial evaluating CD8+-enriched versus unselected tumor-infiltrating lymphocytes for adoptive cell therapy for patients with melanoma. Journal of clinical oncology : official journal of the American Society of Clinical Oncology. 2013; 31:2152-2159.

28. Besser MJ, Shapira-Frommer R, Treves AJ, Zippel D, Itzhaki O, Hershkovitz L, Levy D, Kubi A, Hovav E, Chermoshniuk N, Shalmon B, Hardan I, Catane R, Markel G, Apter S, Ben-Nun A, et al. Clinical responses in a phase II study using adoptive transfer of short-term cultured tumor infiltration lymphocytes in metastatic melanoma patients. Clinical cancer research : an official journal of the American Association for Cancer Research. 2010; 16:2646-2655.

29. Poschke I, Lovgren T, Adamson L, Nystrom M, Andersson E, Hansson J, Tell R, Masucci GV, Kiessling R. A phase I clinical trial combining dendritic cell vaccination with adoptive $\mathrm{T}$ cell transfer in patients with stage IV melanoma. Cancer immunology, immunotherapy. 2014; 63:1061-1071.

30. Tada F, Abe M, Hirooka M, Ikeda Y, Hiasa Y, Lee Y, Jung NC, Lee WB, Lee HS, Bae YS, Onji M. Phase I/II study of immunotherapy using tumor antigen-pulsed dendritic cells in patients with hepatocellular carcinoma. International journal of oncology. 2012; 41:1601-1609.

31. Pan K, Li YQ, Wang W, Xu L, Zhang YJ, Zheng HX, Zhao JJ, Qiu HJ, Weng DS, Li JJ, Wang QJ, Huang LX, He J, Chen SP, Ke ML, Wu PH, et al. The efficacy of cytokineinduced killer cell infusion as an adjuvant therapy for postoperative hepatocellular carcinoma patients. Annals of surgical oncology. 2013; 20:4305-4311.

32. Sawada Y, Yoshikawa T, Nobuoka D, Shirakawa H, Kuronuma T, Motomura Y, Mizuno S, Ishii H, Nakachi K, Konishi M, Nakagohri T, Takahashi S, Gotohda N, Takayama T, Yamao K, Uesaka K, et al. Phase I trial of a glypican-3-derived peptide vaccine for advanced hepatocellular carcinoma: immunologic evidence and potential for improving overall survival. Clinical cancer research: an official journal of the American Association for Cancer Research. 2012; 18:3686-3696.

33. Palmer DH, Midgley RS, Mirza N, Torr EE, Ahmed F, Steele JC, Steven NM, Kerr DJ, Young LS, Adams DH. A phase II study of adoptive immunotherapy using dendritic cells pulsed with tumor lysate in patients with hepatocellular carcinoma. Hepatology. 2009; 49:124-132.

34. Thomas NE, Busam KJ, From L, Kricker A, Armstrong BK, Anton-Culver H, Gruber SB, Gallagher RP, Zanetti R, Rosso S, Dwyer T, Venn A, Kanetsky PA, Groben PA, Hao H, Orlow I, et al. Tumor-infiltrating lymphocyte grade in primary melanomas is independently associated with melanoma-specific survival in the population-based genes, environment and melanoma study. Journal of clinical oncology : official journal of the American Society of Clinical Oncology. 2013; 31:4252-4259.

35. Lee CL, Ko YC. Hepatitis B vaccination and hepatocellular carcinoma in Taiwan. Pediatrics. 1997; 99:351-353.

36. Chang MH, You SL, Chen CJ, Liu CJ, Lee CM, Lin SM, Chu HC, Wu TC, Yang SS, Kuo HS, Chen DS. Taiwan Hepatoma Study G: Decreased incidence of hepatocellular carcinoma in hepatitis B vaccinees: a 20-year followup study. Journal of the National Cancer Institute. 2009; 101:1348-1355.

37. Lok AS, Everhart JE, Wright EC, Di Bisceglie AM, Kim HY, Sterling RK, Everson GT, Lindsay KL, Lee WM, Bonkovsky HL, Dienstag JL, Ghany MG, Morishima C, Morgan TR. Group H-CT: Maintenance peginterferon therapy and other factors associated with hepatocellular carcinoma in patients with advanced hepatitis C. Gastroenterology. 2011; 140:840-849. quiz e812.

38. Bernardinello E, Cavalletto L, Chemello L, Mezzocolli I, Donada C, Benvegnu L, Merkel C, Gatta A, Alberti A. 
Long-term clinical outcome after beta-interferon therapy in cirrhotic patients with chronic hepatitis C. TVVH Study Group: Hepato-gastroenterology. 1999; 46:3216-3222.

39. Valla DC, Chevallier M, Marcellin P, Payen JL, Trepo C, Fonck M, Bourliere M, Boucher E, Miguet JP, Parlier D, Lemonnier C, Opolon P. Treatment of hepatitis C virusrelated cirrhosis: a randomized, controlled trial of interferon alfa-2b versus no treatment. Hepatology. 1999; 29:1870-1875.
40. Nishiguchi S, Kuroki T, Nakatani S, Morimoto H, Takeda T, Nakajima S, Shiomi S, Seki S, Kobayashi K, Otani S. Randomised trial of effects of interferon-alpha on incidence of hepatocellular carcinoma in chronic active hepatitis C with cirrhosis. Lancet. 1995; 346:1051-1055.

41. Shanshan Jiang, Yan Tang, Ke Pan, Desheng Weng, Jia He. In Vitro Culturing and Characteristics of Tumor-infiltrating Lymphocyte of Hepatocellular Carcinoma. Chinese Journal of Cell Biology. 2014; 36:970-975. 